
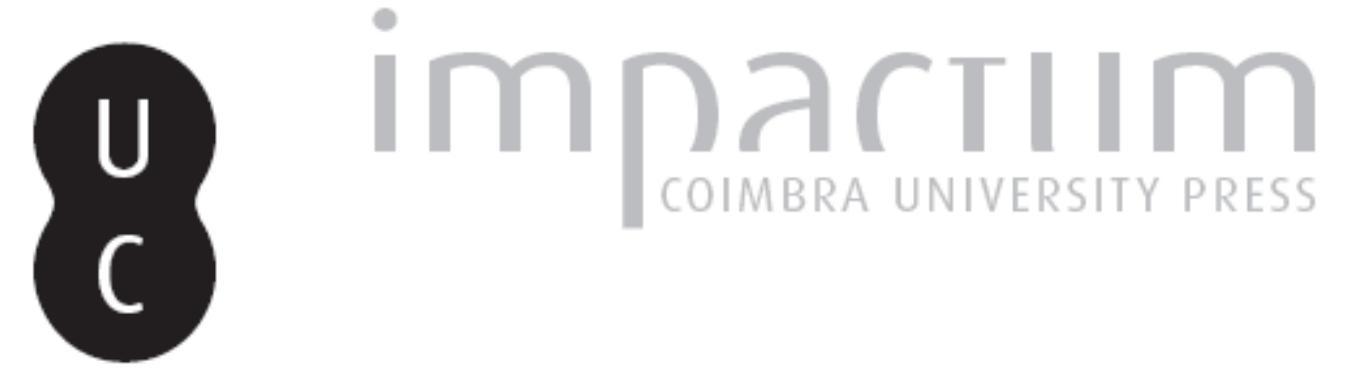

\title{
A receção da Psicologia aristotélica (séc. XVI) em Roma e em Coimbra
}

Autor(es): $\quad$ Carvalho, Mário Santiago de

Publicado por: Faculdade de Letras da Universidade de Coimbra, Instituto de Estudos

URL

persistente:

URI:http://hdl.handle.net/10316.2/35601

DOI:

DOI:http://dx.doi.org/10.14195/0872-0851_45_5

Accessed : $\quad$ 26-Apr-2023 12:42:05

A navegação consulta e descarregamento dos títulos inseridos nas Bibliotecas Digitais UC Digitalis, UC Pombalina e UC Impactum, pressupõem a aceitação plena e sem reservas dos Termos e Condições de Uso destas Bibliotecas Digitais, disponíveis em https://digitalis.uc.pt/pt-pt/termos.

Conforme exposto nos referidos Termos e Condições de Uso, o descarregamento de títulos de acesso restrito requer uma licença válida de autorização devendo o utilizador aceder ao(s) documento(s) a partir de um endereço de IP da instituição detentora da supramencionada licença.

Ao utilizador é apenas permitido o descarregamento para uso pessoal, pelo que o emprego do(s) título(s) descarregado(s) para outro fim, designadamente comercial, carece de autorização do respetivo autor ou editor da obra.

Na medida em que todas as obras da UC Digitalis se encontram protegidas pelo Código do Direito de Autor e Direitos Conexos e demais legislação aplicável, toda a cópia, parcial ou total, deste documento, nos casos em que é legalmente admitida, deverá conter ou fazer-se acompanhar por este aviso.

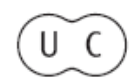




\section{REVISTA FILOSÓFICA DE COIMBRA}

vol. 23 - número 45 - março 2014

vol. 23 - número 45 - março 2014 Fundação Eng. António de Almeida

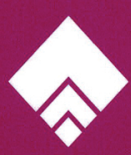




\title{
A RECEÇÃO DA PSICOLOGIA ARISTOTÉLICA (SÉC. XVI) EM ROMA E EM COIMBRA
}

\author{
MÁRIO SANTIAGO DE CARVALHO*
}

Resumo: Confrontam-se as propostas de Bento Pereira (1535-1610), de Manuel de Góis (1543-1597) e de Baltasar Álvares (1560-1630) a respeito da psicologia aristotélica, incidindo em especial na relação com a metafísica, com o estatuto do pensamento e com o problema do chamado averroísmo.

Palavras-chave: Aristotelismo, Psicologia, Metafísica, Teologia, Antropologia, Averroísmo, Conimbricenses, Bento Pereira

Summary: Benet Perera's (1535-1610), Manuel de Gois' (1543-1597) and Baltasar Alvares' (1560-1630) Aristotelian psychologies are here confronted, paying special attention to the status of metaphysics, of thought, and to the problem of the so-called Averroism.

Keywords: Aristotelianism, Psychology, Metaphysics, Theology, Anthropology, Averroism, Conimbricenses, Benet Perera

\section{Geografia e Filosofia}

Serão sobretudo três os professores de filosofia jesuítas de que aqui nos ocuparemos. Uma vez que pudemos apresentar já noutros lugares os dois autores portugueses ${ }^{1}$, deixemos algumas palavras de apresentação sobre

* Departamento de Filosofia, Informação e Comunicação da Faculdade de Letras da Universidade de Coimbra. O artigo resume em português as lições proferidas pelo autor ao curso de mestrado da Universidade de Salamanca, em novembro de 2013.

1 Cf. M.S. de Carvalho, "Introdução Geral”, in Comentários do Colégio Conimbricense da Companhia de Jesus Sobre os Três Livros Da Alma de Aristóteles Estagirita. Tradução do original latino por $\mathrm{M}^{\mathrm{a}}$ da C. Camps, Lisboa 2010, 9-12 e passim. 
Bento Pereira, também denominado Benet Perera (Benedictus Pererius sob a forma latinizada) ${ }^{2}$. Este jesuíta valenciano ensinou "psicologia" em Roma eventualmente nos anos 1566/67 e em 1576 publicou a sua obra prima de filosofia, De communibus omnium rerum naturalium principiis et affectionibus libri $X V^{3}$. Pereira é também conhecido por um ensino muito relevante no campo da teologia (1567/70) e sobretudo no domínio dos estudos bíblicos (1576/90). Toda a sua carreira universitária decorreu em Roma, logo que, perfazendo dezassete anos ingressa na Companhia de Jesus em 1553. O Colégio Romano da Companhia havia sido fundado por Inácio de Loyola apenas dois anos antes. Imediatamente após o curso de Filosofia, Pereira ensina sucessivamente a filosofia natural (1558), a metafísica (1559-1561), a lógica (1561-1562 e 1564-1565), e de novo a física (1562-1563 e 1565-1566) e a metafísica (1563-1564 e 1566-1567). Em virtude da sua competência e renome, a sua carreira não termina na filosofia, e em 1567-1570 ensina teologia escolástica e em 1576-1590 exegese ou teologia bíblica (sacra scriptura). Nos anos 60 ele é acusado de simpatia para com Averróis ou mesmo de "averroísta", um mal a extirpar, dizia-se; sabemos hoje, porém, que Pereira opunha-se, como seria natural, aliás, ao monopsiquismo averroísta, ironizando designadamente sobre uma possível identidade entre o Espírito Santo e o intelecto agente ${ }^{4}$. O que é relevante sim, para já se assinalar, é o facto de 1576 ser a data que assiste à publicação da sua obra prima de filosofia, como dissemos, mas também à sua ascensão profissional à cadeira de Teologia.

Durante os anos em que decorria esta extraordinária carreira docente de Pereira, a mais de $2300 \mathrm{~km}$, nas cidades portuguesas de Coimbra e de Évora, os seus confrades da Companhia de Jesus também comentavam o De anima de Aristóteles. Um manuscrito de Coimbra atribuído a Pedro da Fonseca sobre os dois primeiros livros daquela obra aristotélica estendem-se de novembro de 1559 a fevereiro de $1560^{5}$; em 5 de janeiro de 1568 Pedro Luís,

2 Cf. E.M. Rompe, Die Trennung von Ontologie und Metaphysik. Der Ablösungsprozess und seine Motivierung bei Benedictus Pererius und anderen Denkern des 16. und 17. Jahrhunderts, Bonn 1968, 34-36; P.R. Blum, "Benedictus Pererius: Renaissance Culture at the Origins of Jesuit Science", Science \& Education 15 (2006) 279 sg.; R. Garcia Villoslada, Storia del Collegio Romano dal suo inizio (1551) alla sopressione della Compagnia di Gesù (1773), Roma 1954.

3 Benedicti Pererii S.I. De Communibus omnium rerum naturalium principiis et affectionibus libri $X V$, Lugduni 1585 (doravante citada: De communibus).

4 Cf. P.R. Blum, "Benedictus" 283.

5 In Aristotelis de Anima Scholia, Ms. Coimbra, BGUC 2399. Pleiteando recentemente pela atribuição deste ms anónimo a Pedro da Fonseca, na esteira de F. Stegmüller (Filosofia e Teologia nas Universidades de Coimbra e Évora no século XVI, trad., Coimbra 1959), vd. $\mathrm{M}^{\mathrm{a}}$ da C. Camps, "O visível e a visão no Manuscrito 2399 atribuído a Pedro da Fonseca. Nota de investigação sobre o Capítulo VII do Livro II do 'Comentário ao 'De Anima' de Aristóteles”, Revista Filosófica de Coimbra 22 (2013) 387-396. 
um espanhol também de Valência como Pereira, concluiu o seu ensino sobre a mesma obra de Aristóteles na Universidade Jesuíta de Évora; nos anos 80, de novo em Coimbra, era a vez de Marcos de Moura fazer o mesmo, década em que, seguramente, Manuel de Góis estava já a redigir o seu Comentário ao mesmo título aristotélico preparando-o para a impressão, contribuindo com mais um volume para o internacionalmente famoso Curso Filosófico-Aristotélico Jesuíta Conimbricense ${ }^{6}$; mais ainda: se é verdade que esse volume só foi publicado em 1598, ainda em 1590 Pedro Álvares, e em 21 de março de 1591 Cristóvão Gil, concluíam os seus cursos sobre o De Anima, este último tendo-o começado em $1590^{7}$.

Infelizmente, à exceção do trabalho de Manuel de Góis, com o volume postumamente publicado graças à intervenção de Baltasar Álvares (precisamente o editor do De Anima de F. Suárez), que também assina em apêndice ao referido volume um Tractatus de anima separata, nenhum outro trabalho de psicologia dos jesuítas acabados de citar viu a publicação, e todos eles esperam ainda edições e estudos atentos. Seja como for, ao confrontarmos a proposta romana e a conimbricense, é importante termos presente a sua contemporaneidade, o facto, enfim, de estarmos perante aquilo que chamaremos anacronicamente duas propostas de Programa de Psicologia Jesuíta. Tanto quanto sabemos, é no seio do calvinismo (1574) que o discípulo de P. La Ramée, Johannes Thomas Freig (Freigius), cunha o vocábulo "psychologia", mas sendo embora certo que a cunhagem se insere numa alargada querela sobre a partição das disciplinas e que ela é contemporânea dos autores ibéricos que estamos a tratar, estes nunca empregam tal vocábulo ${ }^{8}$. O interesse deste confronto resulta do facto da distância geográfica que separa as duas penínsulas e não tanto de qualquer diferença temporal relevante. Como já escrevi noutra ocasião, distintamente do critério histórico, o critério geográfico é mais sensível à dimensão do poder $^{9}$, aspeto que aqui será também importante, apesar de em ambos os

6 Para uma identificação completa dos vários volumes do Curso, vd. M.S. de Carvalho, "Introdução" 10-12. Daqui para a frente identificaremos os volumes a citar da seguinte maneira: An para o Comentário ao 'De Anima'; As para o 'Tractatus de Anima Separata'; Ph para o Comentário aos livros da 'Physica'; Gc para o Comentário ao 'De Generatione et Corruptione'; Co para o Comentário ao 'De Coelo'; e Sa para o Comentário aos 'Segundos Analíticos', cada uma destas abreviaturas logo seguida, sem mais, das indicações do livro ou disputa ou proémio, questão, artigo e páginas.

7 Commentarii in libros de Anima Aristotelis a Christophoro Aegidio, Ms Lisboa, BNP 2518.

8 Cf. M. Lamanna, "On the Early History of Psychology", Revista Filosófica de Coimbra 19 (2010) 301.

9 Cf. M. S. de Carvalho, «Acidentais ocidentes e a surdez de Aristóteles. Para uma geografia da Filosofia» Biblos n.s. 2 (2004) 189-218 
casos, Pereira e Góis, discutirem, pelo menos em tese, a liberdade de se antepor a razão à autoridade. É o que se verifica pela leitura da seguinte passagem de Góis: "Quem adere às opiniões de um filósofo, por maior que seja o seu engenho e excelente a sua doutrina, não se afastando dele nem uma unha, expõe-se a ser considerado como alguém que não pretende explorar a verdade da doutrina, mas sim seguir a preconcebida autoridade do mestre (doctor). Nada é mais alheio ao verdadeiro filósofo, a saber, a quem pesquisa a verdadeira sabedoria, do que ser mais amigo de Platão do que amigo da verdade." 10 É também este, precisamente, o motivo glosado por Pereira no Praefatio da sua obra, na qual se viu "a inauguração de uma nova relação com a autoridade"11.

\section{Metafísica e Psicologia}

São muitas as afinidades entre os dois programas, não obstante, e desde logo, o estilo literário adotado ser diferente. De facto, enquanto B. Pereira escreve algo próximo de um tratado de filosofia natural, M. Góis preferirá o comentário filosófico, mas o seu editor, B. Álvares, também optará por um tratado, de metafísica embora. Pereira e Góis partilham de uma mesma conceção de introdução à filosofia, aliás afim ao horizonte renascentista ${ }^{12}$. Isto revela-se quando comparamos as doxografias e as páginas e questões que abrem o De communibus e a Physica, esta última a verdadeira introdução ao Curso Jesuíta Conimbricense publicado. Outros aspetos comuns dizem respeito à preocupação com as duas definições aristotélicas de alma, ponto prévio para a determinação da psicologia, e o enquadramento e a importância desta no âmbito mais vasto mas problemático da ciência moral; neste particular, há um primeiro aspeto a assinalar, pois enquanto em Pereira a dependência dos princípios da scientia moralis em relação aos princípios da scientia animae aparece apoiada na autoridade de Averróis ${ }^{13}$, para Góis essa relação é pensada num quadro que ultrapassa a mera subor-

10 GnIc4q27p2.

11 De communibus, Praefatio, p. 4; cf. M. Lamanna, «'De eo enim metaphysicus agit logice'. Un confronto tra Pererius e Glocenius» Medioevo 34 (2009) 327; vd. também P.R. Blum, "Benedictus" 286.

12 Cf. P.R. Blum, "Benedictus" 291, sem contudo fazer qualquer referência às demais publicações jesuítas.

13 De communibus I c. 4, p12: “... scientia moralis magna ex parte pendet a scientia animae; nam divisio habituum et virtutum moralium pendet ex distinctione potentiarum animae. Distinctio etiam passionum et quae de foelicitate traduntur supponunt multa ex Philosophia naturali. (...) Averroes quoque ait in $\mathrm{I}^{\mathrm{a}}$ de Anima com. $2^{\circ}$ scientiam de anima dare multa principia Philosophiae morali.” 
dinação das ciências práticas às especulativas. O jesuíta português escreve: "a excelência de tal ciência deteta-se no seu rigor demonstrativo, na sua matéria, nobreza e utilidade para a vida, para o conhecimento da verdade, para a moral, para a vida comum e os costumes"14; e noutra passagem do mesmo comentário, continua: "comunicando com a filosofia primeira ou metafísica ela é igualmente útil para toda a filosofia (universam philosophiam) e, dada a sua natureza intermédia, como que um compêndio das coisas humanas e divinas". ${ }^{15}$ A importância da ciência da alma racional ou intelectiva, permite a ambos os autores a defesa de uma posição intermédia para a ciência da alma: "a alma racional ocupa um lugar intermédio entre as formas completamente abstratas e as formas completamente materiais", escreve Pereira ${ }^{16}$. E Góis, por seu lado, dirá: "a alma racional encontra-se no horizonte da eternidade e do tempo" 17 , razão pela qual, o Homem, dada esta sua posição entre o tempo e a eternidade ${ }^{18}$, é o horizonte dos seres materiais e dos seres imateriais ${ }^{19}$. Num e noutro autor, tal não equivale a qualquer autonomização epistemológica da psicologia, embora Pereira admita, opondo-se a Averróis, a constituição de uma quarta (a pneumatologia, digamos) e até mesmo de uma quinta (a teologia natural) ciência especulativa $^{20}$. Considerando o horizonte totalizante (universam philosophiam) da animae meditatio Góis apresenta-a como um trabalho intermédio, acolhe a leitura de Santo Agostinho (no De Anima ele chega mesmo a citar o mote dos Solilóquios), recorre ao Oráculo de Delfos, apela para o Asclépio de Hermes Trismegisto, para o Liber de Causis, acabando por recomendar a leitura de Ficino, de Bessarion e de Pico, juntamente com Tomás ${ }^{21}$. É

\section{Anprp1.}

15 AnIc1qna2p8; PhIIc1q4a2p229.

16 De communibus I c.7, p25: “... anima rationali quae media est inter formas omnino abstratas et formas omnino materiales."

17 PhIc9q12a7p211.

18 PhIc9q12a7p211; Anprp2.

19 CoIIc1q2a2p141.

20 De communibus I c. 4, p. 25: "Non solum autem non est absurdum ponere quartam scientiam speculativam, sed etiam qui poneret quintam quandam, hoc est scientiam Dei, secundum ea quae possunt de eo naturaliter cognosci, distinctam a scientia intelligentiarum, is iudicio nostro non pessime sentiret." A propósito da designação "pneumatologia" que no entanto não comparece nos autores aqui estudados, vd. Anónimo, Biblioteca Geral da Universidade de Coimbra, Ms. 2401, fol. 1r: «Quoniam vero duae potissimum sunt spirituales substantiae, quae rationis viribus a nobis deprehendi valent, spiritus scilicet increatus et summus, ut Deus, infimus et creatus, ut anima et angelus. Pneumathologia aptissime distribuitur in psychologiam, quae de anima agit, et in theologiam naturalem, quae de Deo praetactatur."

21 PhIc9q12a7p.211. 
assim que o estudo da alma se apresenta como uma totius mundi summa; entendamo-nos: ou uma ciência compendiosa da totalidade ou uma ciência suprema, de fronteira. Quer interpretemos esta expressão latina num ou noutro sentido, em Coimbra a scientia de anima deve confrontar-se exclusivamente com a física e com a separação metafísica.

Ponto saliente da divergência entre os dois programas reside na compreensão da metafísica e da relação que esta deve manter com a psicologia, ou vice-versa. No estrito campo da metafísica importa termos presente as indecisões de todas as propostas, a romana e a coimbrã, mas é claro que, se ambas partilham de uma primeira divisão aristotélica das ciências especulativas (física, metafísica e matemática), a principal diferença está no facto de Góis insistir na unidade da metafísica e de Pereira dividi-la ${ }^{22}$. Fá-lo de três maneiras. Primeiro, diz serem três as partes da metafísica: uma principal, e como que final, que versa as inteligências e Deus; outra, os transcendentais: ser, uno, verdadeiro, bom, ato e potência; a última, os dez predicamentos; e acrescenta: a primeira é a mais nobre, a segunda mais universal, a terceira completa as restantes ${ }^{23}$. Logo a seguir, e em nome do que se nos afigura ser uma diferença epistemológica e ontológica (e esta numa aceção algo próxima da de Heidegger ${ }^{24}$ ), Pereira propõe que se subdivida a primeira, haja em vista, respetivamente, o escasso conhecimento natural humano a respeito das inteligências ${ }^{25}$ e a enorme incomensurabilidade entre estas e Deus, "maiorem esse distinctionem inter scientiam Dei et scientiam intelligentiarum, quam est inter scientiam intelligentiarum et scientiam rerum naturalium." 26 Os especialistas têm visto aqui uma crítica ao modelo unitário da metafísica segundo o paradigma katholou/protologico (na terminologia de R. Brague ${ }^{27}$ ), além de uma "profunda indecisão" (agora nas palavras de Courtine ${ }^{28}$ ), nomeadamente em torno da separação da metaphysica em ciência de Deus e em ciência das inteligências. Ponderando tudo, M. Lamanna concluía não

22 De communibus I c. 5, p. 15; Phprq1a2p7.

23 De communibus I c. 6, p.22.

24 De communibus I c. 7, p. 26: "Maior est distantia et diversitas inter Deum et intelligentias quam inter has et res naturales, siquidem maior est distantia inter finitum et infinitum quam inter duo finita. (...) Deus autem ab omni ratione materiae, qualiscunque ea sit, est purus et liber."

25 De communibus I c 7, p. 24; P.R. Blum, "Benedictus" 288 atenta que esta proposta de Pereira é apresentada a título de probabilidade, "which (...) indicates how much he was aware of the noverlty of his proposal".

${ }^{26}$ De communibus I c. 7, p. 25.

27 Cf. R. Brague, Aristote et la question du monde. Essai sur le contexte cosmologique et anthropologique de l'ontologie, Paris 1988.

28 Cf. J.F. Courtine, Suárez et le système de la métaphysique, Paris 1990, p. 474. 
haver ali uma solução coerente ${ }^{29}$, mas o mesmo acontece, infelizmente, em Coimbra. Acresce não ser fácil determinar a visão conimbricense a respeito da metafísica, nem sequer ser certo que a defesa, por Góis, de uma só metafísica visasse a posição do seu confrade romano ${ }^{30}$, embora seja certo que Góis e Pereira criticam o monismo epistemológico de António Bernardi ${ }^{31}$. $\mathrm{O}$ que temos em Coimbra, ou melhor o que não temos, é um comentário à Metafisica, salvo, é claro, a obra imponente, mas inacabada de Fonseca ${ }^{32}$. Também sabemos que vários foram os jesuítas portugueses e espanhóis que em Coimbra e Évora se dedicaram àquela obra de Aristóteles, mas que nunca chegaram a escrever destinado à publicação qualquer Comentário, apesar de M. Góis e Sebastião do Couto o terem constantemente projetado.

A este respeito interessam-nos sobretudo as palavras de Góis, de Álvares e de Couto, os três principais responsáveis pelo Curso publicado. Na Physica Góis contraria a tripla divisão em teologia, em pneumatologia e em ontologia (ou, nas suas próprias palavras, respetivamente, ciência de Deus, ciência das inteligências e ciência dos transcendentais e géneros supremos ${ }^{33}$ ). Reparemos que esta tríplice classificação não corresponde exatamente à primeira formulação de Pereira, que começa por não distinguir a ciência das inteligências da teologia, e separa em duas partes o estudo dos transcendentais e o estudo das categorias ${ }^{34}$. Mas a diferença principal na abordagem da metafísica reside no facto de em Coimbra ela ir assumir uma estrutura teológica e ontológica de contornos dinâmicos pseudo-dionisíacos. Aplicada à psicologia, tal significa que a separação metafísica da alma se funda na consideração da alma racional como forma material suprema sob a regra ontológica dinâmica

29 M. Lamanna, ”De eo enim” 339: "Questa soluzione, atribuendo alle intelligenze il ruolo di principi del soggetto della filosofia prima (...) non puo che ingenerare una ricaduta dell'intero modelo metafísico proprio all'interno di un paradigma katholou-protologico, determinando un'imprevista 'invadenza' dell'ambito speciale in quello universale."

30 Cf. M. Lamanna, "De eo enim" 340, nota 58; PhIq1a2p7.

31 Cf. De communibus I c. 8, pp. 26-30; M.S. de Carvalho, Psicologia e Ética no Curso Jesuita Conimbricense, Lisboa 2010; Id., «Tra Fonseca e Suárez: una metafisica incompiuta a Coimbra» Quaestio. Annuario di storia della metafisica 9 (2009) 41-59.

32 Cf. A. Martins, "Pedro da Fonseca e a recepção da 'Metafísica' de Aristóteles na segunda metade do séc. XVI", Philosophica 14 (1999) 165-178; Id., "A metafísica inacabada de Fonseca" Revista Portuguesa de Filosofia 47 (1991) 526-27.

33 Phprq1a2p7.

34 De communibus I c. 6, p. 22: “... tres partes esse Metaphysicae ac proinde triplicem esse considerationemeius: una est principalis et quasi finis caeterarum (propter quam talis scientia dicitur metaphysica, theologia et omnium nobilissima) in qua tractantur res seiunctae a materia secundum rem et rationem, cuiusmodi sunt intelligentiae et Deus. Altera est pars in qua declarantur transcendentia, ut ens, unum, verum, bonum, actus, potentia, propter quam partem metaphysica dicitur universalíssima et habere eius imperium in caeteras scientias. Tertia pars eius complectitur decem praedicamenta..." 
que dizia: "a parte mais elevada do mais baixo tocar na parte mais baixa do mais alto"35. Pseudo-Dionísio é, assim, uma autoridade nuclear. Apelidado de 'príncipe dos teólogos'36, ele comparece no Curso Jesuíta Conimbricense como defensor da doutrina peripatética ${ }^{37}$, e, além de ser designado como teórico do amor divino ${ }^{38}$, o seu axioma hierárquico acabado de citar é uma trave mestra de interpretação frequentemente utilizado por todo o Curso Jesuíta Conimbricense ${ }^{39}$. Na Logica, Couto irá referir-se a uma metaphysica supernaturalis cuja tarefa é considerar a dependência das essências em relação à Causa primeira ${ }^{40}$; e sob um ponto de vista não descendente, mas ascendente, Góis aludirá a uma divina philosophia como um conhecimento que transcende a natureza (transnaturalium) e no qual a inteligência humana atinge o ápice contemplativo ${ }^{41}$. Temos assim que, num caso (o de Pereira) a metafísica se define na separação relativamente à teologia, o que não suceda no outro (o de Góis).

\section{Psicologia racional}

Se passarmos agora ao estatuto da psicologia racional sobressai imediatamente a profunda diferença dos dois modelos: para Pereira o horizonte de consideração da alma na sua última dimensão é tríplice, ou mesmo quádruple, para Góis apenas dúplice. O aspeto crucial aqui é o do estatuto da alma "racional" ou "intelectiva", nas designações preferidas respetivamente por Pereira e Góis. Segundo este último, o exame da alma pertence à física, quer quando esta se dedica às formas imersas na matéria - o estado da alma ligada ao corpo - quer quando estuda a essência da alma; para a metafísica fica a consideração da alma separada do corpo $^{42}$.

35 AnIc1qna2p8.

36 PhVIIIc6q1a2p776.

37 CoIc2q6a2p45. P.R. Blum, "Benedictus" 290 cita no entanto obra manuscrita de Pereira onde a tradição neoplatónica, e mormente Pseudo-Dionísio, parecem ser relevantes; contudo, isso não acontece nas páginas publicadas do De communibus.

38 PhIIc7q22a2p341.

39 Anprqna2p7; PhIc1q4a1p84.

40 SaIc1q3a3p317.

41 Phprq5a1p38 e ibidem a4p43.

42 AnIc1q1a2p8: "Contemplatio animae secundo modo sumptae transcendit Physiologiae fines, pertinetque ad Methaphysicum. Ad huiusce conclusionis intelligentiam obseruandum est, cum anima rationalis sit suprema formarum in materia existentium, et teste D. Dionysio 7 capite De diuinis nominibus, summum infimi attingat infimum supremi; transire eam, cum e corpore abscedit, pro suo modo in statum substantiarum separatarum, secundum eas uidelicet affectiones, quarum supra meminimus, nihil commercii cum materia habentes, qui status, ut docet D. Thomas I ${ }^{\mathrm{a}}$ part. quaest. 79 art. 1 non est ei naturalis, sed praeter naturam. 
Não assim para Pereira que nega claramente (aperte negamus) e em sentido absoluto (si absolute intelligatur) que "o conhecimento completo da alma racional" (absoluta cognitio animae rationalis) diga respeito a uma ciência una e simples (una et simplex), mas variada e múltipla (varia et multiplex $)^{43}$. Daqui se segue a impossibilidade da física alcançar um conhecimento essencial da alma racional, pois as três prerrogativas desta - separabilidade, imortalidade e uma certa participação em Deus (divina quaedam substantia) -, às quais teremos de voltar, nos obrigam a distinguir o que no horizonte de uma tal ciência é absolutamente físico (omnino Physicas), o que é parcialmente físico (aliquo modo Physicas) e o que é em parte metafísico e em parte teológico (partim Metaphysicam, partim Theologicam) ${ }^{44}$.

Temos assim que sobre a ciência adequada à determinação da essência da alma ambos os autores dissentem sem se poderem encontrar: para Góis, é à física exclusivamente que compete uma tal tarefa, para Pereira não, pois a essência da alma na sua totalidade pertence a vários domínios do saber. Esclareçamo-los bem: o primeiro nível, exclusivamente físico, é irrelevante para a psicologia racional ${ }^{45}$, como veremos, e isto, repetimos, está em claro confronto com Góis ${ }^{46}$. Como se compreenderá, a tese final de Pereira é a de

(...) Scrutari propriam animae naturam, et essentiam, quae erat tertia de animo meditatio, spectat ad naturalem philosophum. Huius conclusionis ueritas ex eo conuincitur, quia anima ex sua ratione et natura, est forma corporis; unde et essentiali definitione explicatur, cum dicitur actus primus corporis organici. Quo fit ut ad sui cognitionem necessario materiam requirat: quae uero ita se habent, infra speculationis physicae metas continentur, sicuti et materia ipsa, docente Aristotele secundo Physicorum cap. 2 text. 22 eiusdem artificis esse materiam et formam contemplari; quia uidelicet duo haec mutuo se respiciunt, ut ex eodem lib. et cap. text. 26 constat. Praeterea stabilitur eadem conclusio ex eo, quia cum homo sit pars subiecta enti mobili, cuius cognitionem Physicus profitetur, cumque hominis essentia cognosci nequeat, quin natura ipsius animae, per quam in suo proprio gradu, et specie constituitur, innotescat: sit inde ut ad naturalem philosophum attineat animae essentiam indagare. Huc pertinet, quod definitio illa hominis passim celebrata, homo est animal constans corpore, et animo rationis participe; a nullo alio praeter quam a naturali philosopho inuenta et tradita esse creditur."; também PhIIc1q4a2p229

43 De communibus I c. 10, p. 37.

44 De communibus I c.10, p. 37.

45 De communibus I c. 9, p. 34, onde se registam em qualquer caso sete argumentos a favor do tratamento pela física da alma; para os procedimentos demonstrativos da física e da metafísica, segundo Pereira, vd. De communibus I c. 8, pp. 28-29.

46 AnIp8: "Prima animae consideratio ad naturalem Philosophiam ex officio spectat. Haec probatur, quia contemplari ens naturale ad Physicum pertinet, eiusdem uero est meditari totum, et partes: at anima eo modo sumpta, est actu pars entis naturalis, nempe hominis. Item quia operationes, quas anima, dum in corpore est, administrat, pendent a materia; et prout connexionem cum ea habent, in considerationem cadunt, non alterius artificis, quam eius, qui de materia disserit, id est, Physiologi.» (os itálicos são nossos). 
que a alma racional, sendo embora uma parte essencial e de algum modo a forma que confere ao ser humano a materialidade, se distingue no entanto das restantes formas físicas e as supera por existir por si, por ser separável e imortal e por participar da eternidade divina ${ }^{47}$. Em que dimensão, e é a segunda situação, é que a alma racional cabe parcialmente à física, ainda segundo Pereira? Só no caso em que, considerando-a imersa na matéria, tratamos do pensamento mediante imagens sensíveis (intelligere per phantasmata), resposta esta, no seu tom genérico, inequivocamente averroísta ${ }^{48}$. Convém anotar que Pereira se confronta aqui diretamente com o que virá a ser um argumento fundamental de Góis - o filósofo natural também se ocupa com a quididade e estuda a definição comum à alma no seu todo, e portanto também com a alma racional ${ }^{49}$ - mas a sua resposta ou aparente solução apenas se limita a insistir nas três prerrogativas da alma racional sob o ponto de vista da pluralidade parcial dos vários saberes que incidem sobre a alma. Também no tocante à questão da separabilidade real e racional (secundum rem et rationem), que é a terceira situação, confrontamo-nos de novo com as três prerrogativas sobressaindo a nota de que a alma tem muito em comum com as inteligências, também elas real e materialmente separadas ${ }^{50}$. Pela psicologia racional passa a fronteira entre a física e a metafísica, de acordo com Góis, e entre a metafísica e a teologia, de acordo com Pereira.

Vários são neste confronto os aspetos problemáticos: a multiplicação, por Pereira, dos acessos cognitivos (chamemos-lhe assim) ao estudo da alma

47 Cf. De communibus VI c. 24, p. 401.

48 De communibus I c. 10, p. 37: “... partim aliquo modo physicas, cuiusmodi est intelligere per phantasmata, esse inseparabilem a materia secundum rem et rationem, atque eo modo vere ac proprie considerari et tractari a physico."

49 De communibus I c. pp. 36-37; AnI p.9: "Scrutari propriam animae naturam, et essentiam, quae erat tertia de animo meditatio, spectat ad naturalem philosophum. Huius conclusionis ueritas ex eo conuincitur, quia anima ex sua ratione et natura, est forma corporis; unde et essentiali definitione explicatur, cum dicitur actus primus corporis organici. Quo fit ut ad sui cognitionem necessario materiam requirat: quae uero ita se habent, infra speculationis physicae metas continentur, sicuti et materia ipsa, docente Aristotele secundo Physicorum cap. 2 text. 22 eiusdem artificis esse materiam et formam contemplari; quia uidelicet duo haec mutuo se respiciunt, ut ex eodem lib. et cap. text. 26 constat. Praeterea stabilitur eadem conclusio ex eo, quia cum homo sit pars subiecta enti mobili, cuius cognitionem Physicus profitetur, cumque hominis essentia cognosci nequeat, quin natura ipsius animae, per quam in suo proprio gradu, et specie constituitur, innotescat: sit inde ut ad naturalem philosophum attineat animae essentiam indagare. Huc pertinet, quod definitio illa hominis passim celebrata, homo est animal constans corpore, et animo rationis participe; a nullo alio praeter quam a naturali philosopho inuenta et tradita esse creditur."

50 De communibus I c.10, p. 37. 
quase não coincide com a proposta de Góis, mesmo no plano da alma separada. E tal acontece não só porque Pereira acrescenta a consideração da teologia, mas sobretudo porque, segundo ele, por um lado, o problema do pensamento só interessa à física na exata medida em que mercê do hilomorfismo não se pode pensar sem a faculdade sensível ${ }^{51}$; por outro lado, porque ao colocar-se na separabilidade a fronteira entre a física e a metafísica, podemos interpretar a separação do conhecimento (a abstração) nos termos de um processo não de desmaterialização mas de imaterialidade. Ou se quisermos, e sem menos ambiguidades de interpretação: Pereira considera ser alheio à filosofia natural o modo como acontece ou como se dá o processo de separação real da matéria, cortando cerce qualquer relação entre materialidade e imaterialidade ${ }^{52}$. Mas há mais: de facto, a discussão sobre a alma racional, em Pereira, nascendo no próprio quadro da discussão sobre as três ciências especulativas ${ }^{53}$, sem deixar de admitir que a metafísica é do âmbito da luz natural ${ }^{54} \mathrm{e}$ visa a dimensão quiditativa ${ }^{55}$, tem dois horizontes claros, o último dos quais impõe a necessidade da própria teologia. O primeiro, em tom histórico-filosófico, digamos, enquadra a discussão em três modelos psicológicos - Alexandre, Averróis e Tomás de Aquino - dizendo explicitamente seguir a posição deste último autor ${ }^{56}$. O segundo horizonte é tanto de natureza epistemológica quanto do âmbito de uma antropologia (digamos assim), na medida em que visa incluir a própria teologia em tal discussão. Para Pereira, a ciência da alma racional não cabe absoluta e totalmente (simpliciter et omnino) na física, mas também não se esgota totalmente na metafísica ${ }^{57}$; muitos assuntos que dizem respeito à psicologia racional, escreve, nem sequer podem ser tratados "por qualquer ciência humana, antes pela ciência sagrada e pela luz da fé infundida em nós por Deus" 58 . Por outras palavras: sendo a alma imortal e consistindo a quididade do ser humano na separabilidade

51 De communibus I c. 10, p. 37: "Placet enim nobis animam rationalem, ut est actus corporis et differentia hominis constituens eum in certo gradu et specie rerum naturalium, et ut ad intelligendum eget opera facultatem sentientem, cognosci et tractari a Physico. "

52 De communibus I c. 10, p. 37: "Sed ea ratione ut est immaterialis, per se subsistens, habens multa cum intelligentiis communia, eam separabilem esse secundum rem a materia, neque cognitionem eius, qua talis est, Physicam esse, sed partim Metaphysicam, partim Theologicam..."

53 De communibus I c. 6, p.18.

54 De communibus I c.8, p. 28.

55 De communibus I c. 9, p. 30.

56 De communibus c. 9, p. 30.

57 De communibus I c. 9, pp.33-34.

58 De communibus I c. 9, p.34: “... ex sacris literis et per lumen fidei nobis divinitus infusum. “ 
e na imortalidade da sua alma ${ }^{59}$, a exclusão desta separabilidade do estudo da física não é suficiente para a identificar com uma indagação metafísica, exigindo por isso o espaço de uma outra ciência - scientia rerum divinarum ${ }^{60}$ - que possibilite a última e cabal compreensão das tantas vezes citadas três prerrogativas da psicologia racional. Não sendo a antropologia uma ciência exclusivamente humana, quatro pelo menos serão os temas que devem ser determinados pela teologia e pela fé (ex sacris litteris et per lumen fidei ${ }^{61}$ ): o último fim e os requisitos para o atingir; o estado da alma racional após a morte; o facto de a imortalidade ser conferida por Deus; a consideração de que uma ciência em parte física, em parte metafísica e em parte revelada nos põe perante uma ciência sumamente difícil, útil e admirável ${ }^{62}$. Dito de maneira lapidar: "multa autem sunt in anima rationali quae longe transcendunt facultatem et considerationem Physici"63.

Enquanto Pereira preferira fazer o seu exame privilegiando o plano das causas, dos efeitos e das operações, a investigação de Góis privilegia a filologia e o comentário, discreteando amplamente em torno das duas definições de Aristóteles sobre a alma (o mesmo procedimento, mas mais lacónico, encontramos em Cristóvão Gil ${ }^{64}$ ). Então, se no quadro da causalidade Pereira exclui a possibilidade da física (physice loquendo) estudar a alma racional: "perspicuum est nullam causam animae rationalis a Physico sciri posse" 65 , é porque Deus é causa eficiente próxima da alma racional, não mediante qualquer movimento físico, tal como a visão de Deus é o

59 De communibus I c. 9, p. 31: "Forma vero, seu proprius gradus formalis, per quem anima rationalis differt et $\mathrm{ab}$ intelligentiis et a caeteris formis naturalibus, continet duo. Unum est, ipsam esse formam materiae cui dat esse, quare differt ab intelligentiis; alterum est non esse formam eductam ex potentia materiae, atque separabilem esse et immortalem, qua nota se cernitur ab alii formis naturalibus. Atque hoc posterius, quod est praecipuum et magis attingit quidditatem animae non potest sciri a physico..." (os sublinhado são nossos).

60 De communibus I c. 9, p. 31; ibidem p 34: “... neque per ullam scientiam humanam sciri possunt de anima rationali..."

${ }^{61}$ De communibus I c. 9 , p. 34

62 De communibus I c 9, pp. 34-35: "Primo, quis sit ultimus finis simpliciter animae rationalis et quae sint necessaria ad talem finem consequendum. Secundo, quis sit status animae rationalis post mortem hominis (...). Tertio. Si animus est immortalis, quonam consilio iunxit illum Deus cum mortali corpore videtur enim monstrosa talis coniunctio (...). Quarta propositio. Hinc necessario efficitur, ut perfecta scientia eorum omnium quae conveniunt animae sit mixta ex tribus doctrinis (...) ex quo fit ut scientia illius maxime difficilis, praestans et admirabilis..."

63 De communibus VII c.22, p. 426.

64 Commentarii in libros de Anima... fol. 104v sg.

65 De communibus I c. 9, p.32. 
seu fim último ${ }^{66}$. Sendo embora parcialmente física - o que se manifesta, repetimos, ao conferir o ser ao Homem, na determinação dos seus movimentos físicos e por este não poder pensar sem o concurso das imagens sensíveis ${ }^{67}$ - a alma racional não se pode confinar à filosofia natural, quer porque ela foi criada a partir do nada, quer pela sua desproporção relativamente ao corpo, isto é, a sua imortalidade, quer finalmente porque a própria atividade de pensar, por si mesma e segundo a sua substância, não é um movimento natural ${ }^{68}$. Mais: como no seu fim último da perfeição a alma racional ultrapassa a natureza (est supernaturalis) - e observemos que o fim é a primeira causa que precede toda a causalidade ${ }^{69}$-, ela também requer necessariamente os meios sobrenaturais (supernaturalia) que tornam possível tal fim ${ }^{70}$. No quadro do estatuto e do significado do pensamento que separa os dois modelos que estamos a confrontar e, com isso, no quadro do próprio horizonte da alma racional ou do Homem, compreende-se que Pereira conclua de modo taxativo que nem subjetivamente, nem efetivamente, nem formalmente, nem objetivamente o pensamento (intelligere) é qualquer coisa de físico ${ }^{71}$.

Seria precipitado e errado pensarmos que Góis e Álvares não têm sobre a alma humana uma conceção tão elevada quanto a de Pereira. Para Álvares também são três as prerrogativas (nobilitas/praerrogativa) da alma racional ou do espírito (anima rationalis vere spiritus): (i) instilado por Deus, sem matéria e, por isso, vindo extrinsecamente; (ii) como que originado do mais íntimo (ex pectore intimisque praecordis) de Deus; (iii) e de elevada condição espiritual imune de qualquer concreção com a matéria ${ }^{72}$. De um ponto de vista genérico, não encontramos diferenças assinaláveis entre Coimbra e Roma. A diferença está em que, em Coimbra, e para tudo simplificarmos, se procura levar a sério, embora de forma não sempre bem sucedida, os fundamentos biológicas da noética (para empregarmos as próprias palavras

66 De communibus I c. 9, p.31.

67 De communibus VII c. 22, pp. 425-26.

68 De communibus VII c. 22, p. 426: "Primo quia anima rationalis non producitur per motum physicum sed per creationem ex nihilo (...). Amplius, quia inter eam et corpus ipsius, non est proportio physica qualis esse debet inter formam et materiam naturalem, siquidem anima rationalis per se est immortalis, corpus autem eius suapte natura est mortale. Deinde, quia propria operatio eius quae est intellectio, per se (et quemadmodum philosophi loquuntur) secundum substantiam suam, non est motus naturalis. "

69 Cf. De communibus VIII c. 4, p. 455; ibidem p. 456: “... sic Deus est finis intelligentiarum..."

70 De communibus VII, c. 22, p. 426.

71 De communibus I c. 9, p.33.

72 Asd1a5p461-2. 
de Libera a respeito de São Tomás ${ }^{73}$ ) ou melhor: os fundamentos naturais da noética. Uma outra diferença notável entre o jesuíta espanhol e o português, relacionada com este ponto, está no facto de Góis considerar que as almas racionais são também essencialmente entes incompletos, ordenando-se transcendentalmente em relação à matéria, enquanto causas formais dos compostos ${ }^{74}$. De facto, a conjugação da alma intelectiva com o corpo visa o bem do todo, e além da alma racional humana conter todas as formas de seres vivos de maneira eminente ${ }^{75}$, só ela permite à espécie humana realizar-se na unidade com o corpo ${ }^{76}$. Em suma, iremos ler no Curso Jesuíta Conimbricense que a alma é mais perfeita no corpo do que fora dele ${ }^{77}$, e sendo verdadeira e propriamente forma do Homem informando o seu corpo enquanto tal ${ }^{78}$, isso deve ser passível de ser confirmado não apenas pela fé mas também mediante argumentos de ordem natural ${ }^{79}$. Finalmente, também em Coimbra se leva a sério o imperativo dogmático da teologia. P. R. Blum teve razão ao sublinhar a sobredeterminação da verdade eterna sobre a natureza do saber no sentir comum da escola ${ }^{80}$, sendo esta uma dimensão sensível do horizonte do poder a que começámos por aludir. Esta dimensão é imperativa na compatibilização de uma leitura naturalista e espiritualista. A alma é também espiritual, como provam os Concílios e os Padres - lê-se em Góis ${ }^{81}$-, sem depender por si do apoio (ministerio) da imaginação (phantasia), na medida em que é a única forma capaz de receber atividades (operationes) espirituais ${ }^{82}$. Mais: as suas operações superam a matéria porque ela forma conceitos de coisas imateriais, como Deus e as substâncias separadas, e percebe esses objetos livres de quaisquer dimensões, figura, cor ou outras afeções corpóreas ${ }^{83}$.

73 A. de Libera, Thomas d'Aquin. L'Unité de l'intellect contre les averroïstes, suivi des Textes contre Averroès antérieurs à 1270, Paris 1997, 210; M. S. de Carvalho, São Tomás de Aquino. A Unidade do Intelecto contra os Averroístas, Lisboa 1999, 168; vd. também De communibus I c. 9, p.30.

74 Asd1a7p467.

75 GcIc4q19a2p144.

76 AnIIc1q6a3p77.

77 AnIIc1q3a2p58.

78 AnIIc1q6a2p74.

79 AnIIc1q6a2p6.

80 P.R. Blum, L'enseignement de la métaphysique dans les collèges jésuites d'Allemagne au XVIIe siècle, in L. Giard (dir.), Les Jésuites à la Renaissance. Système éducatif et production du savoir, Paris 1995, 96.

81 AnIIc1q1a6p41.

82 AnIc1q2a2p51.

83 AnIIc1q1a6p41. 
Os imperativos conciliares não foram só acolhidos pelos jesuítas portugueses, como Góis ou Cristóvão Gil ${ }^{84}$, mas também por Toledo ${ }^{85}$, e vale a pena lembrar que Suárez hesitou sobre o mesmo assunto: se em 1572 ainda defende que o tratamento da separação da alma compete à esfera da teologia $^{86}$, na revisão do texto atribui essa tarefa à metafísica ${ }^{87}$. Recorde-se que o seu editor foi B. Álvares, e se compararmos esta segunda proposta de Suárez com o programa dos seus confrades conimbricenses, além desta vulgar partilha da duplicidade da psicologia - física, enquanto a alma é "forma corporis", metafísica, se entendida como "entitas spiritualis independens in esse a materia, intelligens et volens" 88 - deparamo-nos com uma diferença curiosa: enquanto Suárez remete esta "tendência (...) de raiz platónico-augustinista" ou tónica espiritualizante para o Liber de Anima de Avicena (no sentido em que vê "a alma não apenas como um princípio informativo, mas também dinâmico..." ${ }^{\prime 89}$ ), em Coimbra encontramos antes linhas augustinistas e hu-

84 Commentarii in libros de Anima... fol. 160v.

85 Cf. F. Toletus, Commentaria una cum Quaestionibus in tres libros Aristotelis de Anima III c. 5, q. 16, Coloniae 1615 (ed. G. Olms, Hildesheim 1985), f. 148v-156r.

86 F. Suárez, Commentaria una cum quaestionibus in libros de Anima. Comentários a los libros de Aristóteles 'Sobre el Alma'. Introducción y edición crítica por S. Castellote. Traducción castellana por C. y L. Baciero, tomo I, Madrid 1978, Prooemium p.2: “... illius enim consideratio [sc.: animae separatae] valde theologica est, multumque naturalem scientiam transcendit, et in hac scientia commodiore locum non habet...”; vd. D. Des Chene, Life's Form. Late Aristotelian Conceptions of the Soul, Cornell University Press, Ithaca London 2000, 19.

87 F. Suárez, Commentaria... Prooemium p. 34, n.23: “... de statu illius [sc.: animae] extra corpus, ut de modo essendi et cognoscendi quam tunc habet, magis pertinet ad metaphysicum."; veja-se ainda P. da Fonseca, In Metaphysicorum Aristotelis Stagiritae Libros. I, I, IV, c. 1, q. 1, col. 648-49 (Petri Fonsecae Commentariorum in Metaphysicorum Aristotelis Stagiritae Tomus I-II, Coloniae 1615: rep. Hildsheim, 1964): “... cum sit abstrata re ipsa, non autem ratione (neque enim sine essentiali propensione ad materiam intelligi potest) aliam postulat scientiam a praedictis quatuor et mediam inter eas ac Physicam.”; F. Suárez, Disputaciones... I s. 2, § 20 ed. Romeo, p. 249; F. de Toledo, In Aristotelis libros de Anima, quaestiones prooemiales q. 2 (ed. citada III, pp. 3-4).

88 F. Suárez, Commentaria...Prooemium pp. 18-20, nn 11 e 12: “... absolute dicendum esse considerationem animae rationalis pertinere ad Physicam”; Id., ibid. p. 26, n. 16: "Est ergo de consideratione Physicae anima rationalis cum omnibus proprietatibus suis simpliciter, Metaphysicae vero secundum quid..."

89 S. Castellote, «Introducción», p. LXXI, e passim para a "antropologia suareziana". Cf. G. Verbeke, «Le 'De Anima' d'Avicenne. Une conception spiritualiste de l'Homme», in Avicenna Latinus. Liber de Anima seu Sextus de Naturalibus IV-V, ed. S. van Riet, Louvain - Leiden 1968, mormente pp. 20*-36*. De referir, no entanto, que o apreço de Pereira pela metafísica de Avicena é reduzido, ao ponto de lhe opor o próprio Averróis como autoridade no peripatetismo, vd. De communibus, Praefatio, p. 3. 
manistas compatíveis com uma qualquer deteção do criacionismo na tradição peripatético-tomista.

\section{Teologia e imortalidade da alma}

A separação da alma característica da imortalidade é de ordem preternatural ${ }^{90}$. Mas é porque se trata de um comentário de filosofia aristotélica que Góis e Álvares não concedem grande espaço à indagação da teologia e se limitam a porem-se debaixo da alçada da teologia revelada. Embora o trabalho demonstrativo filosófico de Álvares, por exemplo, não derive da determinação conciliar de Latrão ${ }^{91}$, não deixa de ser verdade que todo o Comentário ao 'De Anima' remete para o Tratado da Alma Separada e que este tem um fito transparente: pode-se provar a imortalidade da alma racional mediante argumentos racionais ${ }^{92}$; certamente que a fé nos diz que ela é imortal ${ }^{93}$, mas também os filósofos tinham dito o mesmo ${ }^{94}$, estratégia de harmonização esta, no seu tom geral, não menos averroísta.

Pereira também não havia ignorado que se podia tratar filosoficamente $o$ tema da imortalidade da alma, quer segundo Platão ${ }^{95}$, quer segundo Aristóteles ${ }^{96}$, quer mesmo segundo a racionalidade não derivada da autoridade ${ }^{97}$. Nos capítulos 19 e 20 do livro das Formas percebemos que o jesuíta valenciano tem como interlocutores explícitos Duns Escoto e Caetano, ambos pleiteando pela impossibilidade de se provar demonstrativamente ou pela razão natural ( $a b$ ullo philosopho demonstrative probatum esse, nec posse naturaliter probari, sed fide tantum a nobis credi) a imortalidade da alma racional. Apesar de ser patente que Álvares cita Caetano mais de vinte vezes e cita Escoto outras tantas não estamos ali perante uma oposição direta ao modelo de Coimbra, mas sim perante o facto de Coimbra e Roma conceberem diferentemente o horizonte daquele trabalho filosófico. Pereira afasta-se dos seus colegas lusitanos porquanto os seus dezasseis argumentos não pretendem ser apodíticos, mas apenas persuasivos (potest etiam ...persuaderi his rationibus $)^{98}$. Ei-los pela ordem em que o autor os refere: (i) a inteligên-

90 Asd2a2p477.

91 Asde1a3p453: “... non usos fuisse nos auctoritate Concilii Lateranensis...”. Veja-se em todo o caso, mais adiante, Asd1a5p458.

92 Asd1a3p447.

93 Asd1a5p459.

94 Asd1alp442.

95 De communibus VI c. 18.

96 De communibus VI c.19.

97 De communibus VI c. 20.

98 De communibus VI, c.20, p. 390 
cia (mens) humana tem uma capacidade infinita para conhecer desmaterializando; (ii) ela reflete sobre si mesma e conhece-se a si mesma; (iii) a sua atividade de abstração visa a perfeição; (iv) o intelecto e a vontade aspiram à eternidade; (v) é inato o desejo da eternidade; (vi) a ordem da liberdade não coincide com a ordem da natureza; (vii) se a matéria prima é incorruptível por maioria de razão o deve ser o intelecto humano; (viii) só o ser humano detém o conhecimento de Deus e tudo o que dele decorre; (ix) nada de limitado preenche o espírito (animum) humano; (x) a consciência do afastamento do mal; (xi) o sinal dado pela ciências e obras humanas; (xii) a dimensão moral da força humana; (xiii) o desejo naturalmente humano de uma fama perpétua; (xiv) a oposição entre a alma racional e as moções do corpo; (xv) o caráter incomparável do último fim dos Homens; (xvi) a providência divina sobre as coisas humanas.

Nem Álvares nem Góis repudiariam estes raciocínios. Alguns deles repetem-se mesmo em Coimbra, como veremos ainda. A diferença está em que aqui se crê na pretensa racionalidade da prova (naturali ratione) da imortalidade da alma racional ${ }^{99}$, sobretudo visando o caráter "ab-soluto" desse subjectum ou suppositum que a alma é, uma "simplex entitas" extremada pelo extrinsecismo da Criação ${ }^{100}$, "vinda da fora" (extrinsecus adveniens) $)^{101}$, alusão bíblica esta colacionada aproblematicamente com De Generatione animalium II 3 (736b27-29) ${ }^{102}$. Enquanto filólogos comentadores de Aristóteles, o que os autores de Coimbra dizem claramente é que o Filósofo pensou a espiritualidade (divinitus creari/immortalem esse) da alma apoiado na ideia da sua imaterialidade (non educi a gremio materiae), e que isso seria o mesmo que sustentar, como no Génesis $(2,7)$, que "o Senhor Deus formou o Homem da terra e insuflou-lhe na face o espírito da vida (spiraculum vitae), criando-o como ser vivente (animam viventem)". Concluindo ser evidente a persistência da alma racional após a morte ${ }^{103}$, Álvares esforça-se por demonstrar como filólogo e como exegeta ${ }^{104}$ que Aristóteles e o dogma católico não se opõem terminantemente. Não obstante o seu rasgo retórico contemporâneo, neste gesto há um patente embaraço, pois ao interpretar a opinião do Filósofo sobre a imortalidade da alma inte-

99 Cf. Asd1a3p447: "Animae rationalis immortalitas naturali ratione demonstratur."

100 Cf. Asd1a3p449.

101 Asd1a5p461.

102 Cf. também De communibus VI, c.19, p. 388.

103 Asd2a1p470: “...liquido constat, eam [sc. animam rationalem] post totius compositi dissolutionem in rerum natura persistere."

104 Não é v.g. esse o procedimento de Cristóvão Gil, ao perguntar "quid senserit Aristotelem de anima immortalitate", in Commentarii... fol. 161v-162v. 
lectiva (mens/ animum humanum) ${ }^{105}$ nos quadros da sua criação por Deus, Álvares não deixa de apelar para um indisfarçável e nunca problematizado contexto neoplatónico. O argumento de Aristóteles do De Generatione animalium é citado pelos autores lusitanos em grego com agrado e interpretado no sentido de uma origem exterior (thyraten) divina (theion) para o espírito humano (noun) ${ }^{106}$; ora, e para clarificarmos o nível da exegese praticado na obra, a leitura como "restat igitur" dos semas gregos "leípetai de" da notável passagem de De Generatione animalium sobre a psicogénese é interpretada no Tratado da Alma Separada como conclusiva, nisso se distinguindo de Pereira e dos naturalistas, mormente Pórcio, o qual, frente à mesma passagem, preferia uma interpretação mais sensível à incerteza e ao tom de pesquisa dessas páginas de Aristóteles ${ }^{107}$. Também Galeno e Platão são convocados em prol da imortalidade da alma. E mesmo admitindo que Galeno permaneceu "naturalmente" em dúvida ${ }^{108}$, Álvares declara explicitamente que Platão (Timeu, Filebo, Ménon e República) foi "acerrimus animorum immortalitatis propugnator et vindex"109. Tudo somado, são pelo menos oito os argumentos gerados pela luz da razão natural que Pereira utiliza (e, acrescentamos nós, sabendo que nem todos eles seriam constringentes no mesmo grau) e que devemos ler em confronto com os dezasseis argumentos apenas persuasivos invocados por Pereira. Ei-los, na ordenação de Álvares: (i) a alma racional é uma substância subsistente por si e espiritual; (ii) o que quer que seja que subsista por si não pode corromper-se por processos

105 Asd1a2p446: “... quibus verbis significat Aristoteles animum humanum non educi e gremio materiae, sed divinitus creari, atque adeo immortalem esse. “

106 Asd1a2p445; também Asd1a5p461; Aristóteles, De Generatione animalium II 3, 736b 26-30: "Leípetai dè tòn noun mónon thyrathen epeisiénai kaì theíon einai mónon: outhèn gàr autou te energeía koinonei somatikè enérgeia." Note-se como v.g. a tradução francesa de P. Louis (Paris 1961) revela uma flagrante afinidade com a tradução conimbricense: "Restat igitur ut mens sola extrinsecus accedat, eaque sola divina sit; nihil enim cum eius actione communicat actio corporalis" - "Reste donc que l'intellect seul vienne du dehors et que seul il soit divin; car une activité corporelle n'a rien de commun avec son activité à lui". Um pouquinho diferente é apenas a tradução inglesa mais corrente (A. Platt, in The Complete Works of Aristotle. Ed. by J. Barnes, Princeton 1995): "It remains, then, for the reason alone so to enter and alone to be divine, for no bodily activity has any connexion with the activity of reason".

107 Cf. a propósito S. Salatowsky, De Anima..., 200-01.

108 Asd1a5p443.

109 Asd1a1p443; vd. também De communibus VI, c18, pp. 386-88, mormente, De communibus VI, c.18, p. 387: “... ita ut apud Platonem idem sit animum moveri a se, quod apud Aristotelem habere propriam operationem non communicabilem corpori.". Também Pereira, sem deixar de insistir no absurdo e na falsidade da reminiscência, admite que a tese platónica coincide com o ensinamento aristotélico. 
naturais; (iii) o ser humano aspira naturalmente à vida eterna; (iv) o êxtase pode acontecer também por processos naturais; (v) é da natureza da alma e das suas faculdades transcender constantemente tudo aquilo que é mutável; (vi) em cada ser humano encontra-se um desejo natural de felicidade; (vii) sendo natural ao Homem viver uma vida moral e virtuosa tanto mais o será a vida imortal; (viii) a providência divina conferiu-nos uma vida imortal. Para tudo complicar/reforçar conjuga-se a passagem de Agostinho da espiritualidade à imortalidade, tanto no seu De immortalitate animae, quanto no tema da "inquietude" humana (Conf. I), ambas as alusões sempre articuladas com o diálogo de Platão sobre a imortalidade da alma (Fédon), o testemunho de Sócrates reportado pelas Tusculanas de Cícero e o De Perenni Philosophia de Eugubino ${ }^{110}$. Dissemos acima que Álvares não ignorava que nem todos os seus argumentos tinham o mesmo valor argumentativo. $\mathrm{O}$ mais interessante é que, invocando retoricamente a aprovação da demonstração física por Duns Escoto no Quodlibet $I X$ e alinhando Tomás e Agostinho do mesmo lado, o jesuíta português visa claramente o luteranismo e, na mesma resposta, eventualmente o próprio Pereira, sustentando que o conhecimento sobrenatural não impede o conhecimento natural (cognitio supernaturalis non impedit naturalem cognitionem eiusdem rei) ${ }^{111}$.

Em vez desta harmonia Pereira retirará a lição de que a imortalidade da alma não compete à metafísica, mas à teologia e à fé. O ponto de partida, no plano das causas e dos efeitos, é Deus, como vimos já. Deus enquanto criador e Deus enquanto objeto da visão beatífica ${ }^{112}$. Tanto para Pereira quanto para Álvares o intelecto e a vontade, e as suas operações, não podem respeitar à filosofia natural porquanto subsistem no estado da alma separada ${ }^{113}$. Todavia, para o autor português do Tratado da Alma Separada, o estudo sobre tal subsistência pertence à metafísica sem que se invalide o lugar da fé como auxiliar para a finitude do conhecimento humano ${ }^{114}$. Para o autor valenciano tratar-se-á sempre e já da teologia.

110 Cf. Asd1a3p449-51. Ibidem, p. 450: "Unde ad alia semper mens anhelat, siquod forte inveniat obiectum, in quo quiescat..."

111 Asd1a3p452. "Oppones tamen non videri posse demonstrari animae nostrae immortalitatem, cum inferius ostendendum sit, id dogma de fide esse. Sed occurrendum non omnia quae fides docet supernaturali cognitione teneri oportere, si alioquin satis sint perspecta naturali lumine..."

112 De communibus I c. 9, p. 31.

113 De communibus I c. 9, pp. 32-33.

114 Asd1a3p452-3: “... cum natural ilumine cognitam esse immortalitatem animae asserimus, non excludere nos peculiaria quaedam auxilia et illustrationes mentium, sine quibus fortasse id assequi non potuerunt philosophi post primi parentis lapsum.” 


\section{Averroísmo}

O dossier relativo ao alegado averroísmo de Pereira tem sido controverso. Tendo tido acesso a um manuscrito das lições sobre o De anima, $\mathrm{P}$. R. Blum afastou a possibilidade de Pereira simpatizar com o averroísmo, não obstante alguma ambiguidade na referência ao filósofo islâmico logo no início do De communibus, e viu antes ali um conjunto circunstancial de acusações ${ }^{115}$. Do que acabámos de dizer depreende-se que Pereira não pode ser acusado sem mais de averroísta, mas que também se pode encarar todo este assunto de um outro ponto de vista.

Góis e Pereira confrontam-se com o averroísmo de maneira distinta, mas estão de acordo na consideração, em termos averroístas, da tese que defende a existência de uma alma assistente (assidentem) ${ }^{116}$, e no horizonte da crítica a dirigir ao monopsiquismo, a saber: a reivindicação tomista de que é o Homem individualmente considerado que pensa. Não se deve pensar, insiste Góis, que há uma única alma realmente distinta dos indivíduos singulares $^{117}$; outrossim, uma alma em cada ser humano individual ${ }^{118}$. Também Pereira, quando discute se a alma racional é a forma verdadeira e natural do Homem $^{119}$, produz três asserções de recorte tomista. A primeira diz que o Homem é verdadeiramente um ser pensante, e portanto a alma intelectiva é uma forma essencial ${ }^{120}$. A segunda, que a alma racional é uma forma e parte essencial do Homem ${ }^{121}$. Finalmente, a terceira, afirmando que a alma confere o ser ao Homem, nega que ela possa ser uma forma assistente, acabando por concluir que a alma deverá ser a sua forma verdadeira e natural ${ }^{122}$. Não descortinamos muitas diferenças entre a argumentação de Pereira e de Góis; em ambos os casos reforça-se também o horizonte moral da argumentação de São Tomás compatibilizando-o com a definição de Aristóteles, "a alma é aquilo pelo qual vivemos, nos movemos, sentimos e pensamos". A argumentação de Pereira, por exemplo, serve-lhe para fortalecer a tese de que a alma

115 De communibus, Praefatio, p. 3: "De Averroe, quoniam de eo varias multumque discrepantes hominum sententias esse vídeo, dicam breviter, ut sentio. Ego, sicut eos non laudo, qui Averroem fastidiose contemnunt, convitiis lacerant, et veluti pestem ingeniorum, omnibus fugiendum esse clamant, sic contra, quosdam esse, qui eum laudibus in coelum efferant et quasi Deum quendam philosophiae colant eiusque sententias tanquam oracula divinitus edita in veneratione habeant..." Cf. R. Blum, "Benedictus" 283, e 284.

116 AnIIc1q7a1p79.

117 AnIIc3exp104.

118 GcIc4q21a2p157.

119 De communibus VI c.20, p. 392; cf. também De communibus I c. 9, p. 30.

120 De communibus VI c21, p393.

121 De communibus VI c22, p. 394.

122 De communibus VI c23, p. 396. 
racional é a forma verdadeira, natural ${ }^{123}$ e essencial do Homem, mas também para, no mesmo lance, negar que ela possa ser uma forma assistente ${ }^{124}$, e assim a oposição Tomás vs. Averróis é nítida. E dado que Pereira contraria a possibilidade da filosofia natural alcançar o conhecimento da alma tendo no horizonte a tese de Averróis ${ }^{125}$, podemos dizer sem receio que essa sua crítica se dirige antecipadamente, em parte, à alegação de Góis sobre a física alcançar à essência da alma. Porque, enfim, a atividade intelectiva mediante imagens sensíveis (intellectio per phantasmata) é uma ação imanente subjetivamente inerente à alma racional ${ }^{126}$, Pereira vê na terceira tese a refutação explícita dos averroístas ("non sit anima rationalis una numero in cunctis hominibus" ${ }^{27}$ ), elencando oito argumentos que evidenciarão a incompatibilidade entre: (i) a unidade e a pluralidade; (ii) o tempo e a eternidade; (iii) o finito e o infinito; (iv) a mobilidade e a imobilidade; (v) conhecer por si e o conhecer por outrem; (vi) a maior celeridade e a menor lentidão (vii) o mesmo e o diverso; (viii) a verdade e a falsidade. Acresce que a sua crítica ao averroísmo repudia (est admodum futile et plane fictitium) a possibilidade de a alma racional poder ser considerada de duas maneiras: enquanto é uma substância completa e as suas operações são independentes do corpo, tal como a inteleção é de certo modo divina e o conhecimento intuitivo como o das inteligências; e enquanto assiste o Homem atuando nele, por um lado, objetivamente mediante o corpo e as imagens sensíveis e, por outro lado, numa operação própria, à semelhança daquela que a inteligência tem relativamente ao céu quando the comunica o movimento circular mas não comunica a inteleção ${ }^{128}$. Notemos que, embora no seu "programa" de psicologia em 1564 Pereira mencionasse "entre os gregos "o nome de Simplício ${ }^{129}$, a versão histórico-filosófica que ele explana e a que acima fizemos referência, omite esse comentador peripatético neoplatónico, autor deveras importante por exemplo quanto ao lugar intermédio do estudo da alma, entre a filosofia natural e a metafísica ${ }^{130}$. Talvez mais atualizada, porquanto nos transmite o

123 De communibus VI c. 21.

124 De communibus VI c. 22, pp. 394-6.

125 De communibus I c. 9, p. 30: “... secundum vero opinionem Averroem eatenus esse physicam (...), simpliciter autem et secundum suam quidditatem esse physicam."

126 De communibus VI c.22, p. 396.

127 De communibus VI c. 23, p. 396.

128 De communibus VI, c.22, p. 395.

129 Cf. M.S. de Carvalho, Psicologia... 51; Id., "Pierre Bayle et la critique d'Averroès à Coimbra. Deux épisodes de l'histoire de la réception d'Averroès“ Revista Filosófica de Coimbra 22 (2013), 417-432

130 Cf. B. Nardi, Saggi sull'aristotelismo padovano dal sec. XIV al XVI, Firenze 1958, 365-443. Simplício é porém referido no Praefatio, vd. De communibus, Praef. p. 2, mas depois amplamente criticado, vd. De communibus IV, c. 10, pp. 238-243. 
seu enquadramento mais geral e neoplatónico nas teses de António Bernardi e de Alessandro Achilini sobre a forma informante, também a versão de Góis nos informa que tese da alma assistente era considerada uma posição averroísta $^{131}$.

Uma vez mais, o ponto a destacar é o que diz respeito ao facto de em Pereira a refutação averroísta se enquadrar numa discussão teológica sobre a imortalidade, em Góis, num âmbito filosófico, qual o da discussão sobre a definição da alma, por Aristóteles (De An. II 1, 412 3- 413ª) e, em Álvares, no capítulo da metafísica cuja capacidade cognitiva se reivindica, sobretudo no contexto da polémica antiluterana. Enfim, no horizonte deste confronto romano e coimbrão está em causa um "discurso decisivo sobre a harmonia entre a religião e a filosofia" (se quisermos recorrer às palavras de Averróis ${ }^{132}$ ), ou (e agora também num título, mas de Leibniz ${ }^{133}$ ) "um discurso preliminar da conformidade da fé com a razão". E neste quadro é relevante a prudência de Pereira ao querer expressamente omitir argumentos abstrusos, afastados do senso comum e da inteligência, ilusórios e mais vulgares do que autenticamente filosóficos, desvalorização ou crítica esta que toca em alguns argumentos de Coimbra, já lembrados. Seja como for, do ponto de vista da "harmonia decisiva", Coimbra representa o triunfo de Averróis, mas outro tanto sucede se tivermos presente esta última crítica que Pereira lança às frágeis expressões retóricas de uma argumentação a favor da imortalidade. Dissociando os dois saberes, e sem beliscar a superioridade da teologia e dos teólogos, a limitação que Pereira traz à filosofia passa a assinalar como crítica toda a argumentação que se queira apodítica, representando por isso um pleito pela limitação do saber natural.

\section{Conclusão}

Enquanto Pereira trabalha já como teólogo, Góis e Álvares veem-se a si mesmos como filósofos, procurando cumprir a tarefa de comentar Aristóteles mas impossibilitados de o fazerem sem uma abertura ao neoplatonismo. Se em ambos os programas de psicologia este saber tem um lugar intermédio, a conceção sobre o seu papel ou lugar diverge, nos seus termos (tempo/eternidade e formas abstratas/materiais) e nos seus modos (uma solução ou tríplice ou dual). Também o entendimento da metafísica não coincide, num caso

131 Cf. AnIIc1q8a1p85.

132 Averróis, Discurso decisivo sobre a Harmonia entre a Religião e a Filosofia. Tradução do árabe, introdução e notas de C. Belo, Lisboa 2006.

133 Cf. G.W. Leibniz, Essais de Théodicée. Discours préliminaire de conformité de la foy avec la raison, $\$ 7$ (ed. C.J. Gerhardt, Bd. 6, rep. Hildsheim 1961, 48). 
separando-se da teologia, noutro apontando para ela; e outra divergência se deteta a respeito do significado do pensar: especialmente natural, segundo Góis, especialmente revelado, segundo Pereira. Do exposto ressaltou, por fim, o facto de em Coimbra se seguirem explicitamente as determinações canónicas mas também o facto de uma tal subserviência relativamente ao poder ter propulsado uma aproximação física à psicologia e a expansão da filosofia natural, este último ponto claramente contrariado por Pereira. Podemos atualizar todo o exposto em dois campos cognitivos distintos, e concluir que se um paradigma de trabalho contemporâneo, como por exemplo o de A. Damásio, parece evidenciar o triunfo de Coimbra, alguma relação atual com a questão da imortalidade da alma, como por exemplo em J. Ratzinger, patenteia antes o triunfo da solução romana. 
